\title{
Chemical interaction of Na with cleaved (011) surfaces of CulnSe ${ }_{2}$
}

Cite as: Journal of Applied Physics 80, 5039 (1996); https://doi.org/10.1063/1.363549

Submitted: 24 June 1996 • Accepted: 30 July 1996 • Published Online: 17 August 1998

A. Klein, T. Löher, C. Pettenkofer, et al.

ARTICLES YOU MAY BE INTERESTED IN

Effects of $\mathrm{Na}$ on the electrical and structural properties of $\mathrm{CuInSe}_{2}$

Journal of Applied Physics 85, 7214 (1999); https://doi.org/10.1063/1.370534

Effect of sodium incorporation into CulnSe 2 from first principles

Journal of Applied Physics 114, 083503 (2013); https://doi.org/10.1063/1.4819105

Efficiency enhancement of $\mathrm{Cu}(\mathrm{In}, \mathrm{Ga}) \mathrm{Se}_{2}$ solar cells due to post-deposition $\mathrm{Na}$ incorporation

Applied Physics Letters 84, 1129 (2004); https://doi.org/10.1063/1.1646758

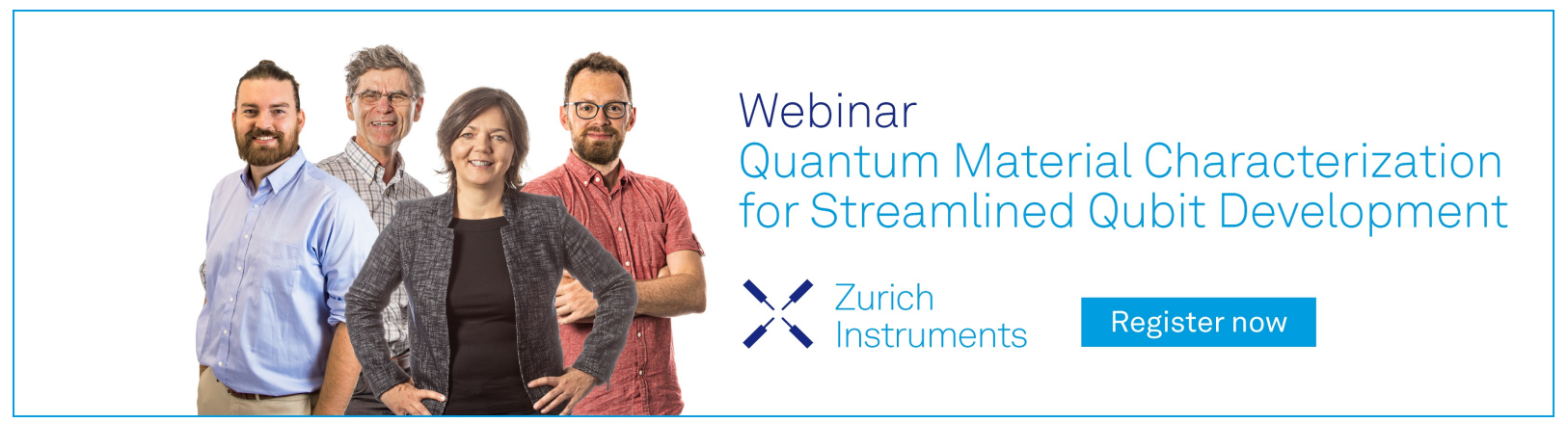




\title{
Chemical interaction of $\mathrm{Na}$ with cleaved (011) surfaces of CulnSe $\mathrm{C}_{2}$
}

\author{
A. Klein, T. Löher, C. Pettenkofer, and W. Jaegermann ${ }^{\text {a) }}$ \\ Hahn-Meitner-Institut, Abt. CG, Glienicker Strasse 100, D-14109 Berlin, Germany
}

(Received 24 June 1996; accepted for publication 30 July 1996)

To study the beneficial effect of sodium-containing substrate material on the photovoltaic properties of thin-film CuInSe $\mathrm{C}_{2}$ solar cells the chemical interaction of $\mathrm{Na}$ with $\mathrm{CuInSe}_{2}$ has been investigated by synchrotron excited photoelectron spectroscopy. A clean $\mathrm{CuInSe}_{2}(011)$ surface was prepared by cleaving an oriented single crystal in UHV. The cleaved surface exhibits an electron affinity of $\chi \approx 4.6 \mathrm{eV}$. The Se $3 d$ level shows a surface core level shift of $-0.4 \mathrm{eV}$. Na was sequentially deposited in UHV in small steps from a commercial dispenser source. Initially ionized Na adsorbs on the surface leading to a shift of the surface Fermi level by $0.3 \mathrm{eV}$ closer to the conduction band. Removal of $\mathrm{Cu}$ from the surface is observed. For higher $\mathrm{Na}$ deposition a chemical reaction of $\mathrm{Na}$ with the $\mathrm{CuInSe}_{2}$ surface occurs leading to the formation of metallic indium and $\mathrm{Na}_{2} \mathrm{Se}$. (C) 1996 American Institute of Physics. [S0021-8979(96)06221-4]

\section{INTRODUCTION}

The chalcopyrite semiconductors have received much attention in recent years. They are ternary analogs of the more common 3-5 or 2-6 compound semiconductors. Their physical properties, however, are more complex than those of their binary counterparts because of the metal $d$-state contribution to the valence-band density of states. ${ }^{1}$ Research on ternary compounds is stimulated by their potential use in advanced optoelectronic devices. CuInSe ${ }_{2}$ has been extensively explored as a thin-film solar cell absorber material. Within the last decade solar cells on the basis of thin-film CuInSe ${ }_{2}$ could be optimized such that efficiencies are now at almost $17 \%$ in laboratory cells. ${ }^{2}$ The physical and chemical properties of the interfaces appearing in the solar cells, however, are not yet completely understood. Since the interfaces may dominate charge carrier transport and lifetime properties a detailed analysis appears worthwhile.

A considerable efficiency leap in the CdS/CuInSe ${ }_{2}$ solar cell system was achieved by the use of soda lime glass as substrate material for thin-film deposition. ${ }^{3}$ Outdiffusion of sodium from the substrate and dispersion into the $\mathrm{CuInSe}_{2}$ layer was evidenced by x-ray photoelectron spectroscopy (XPS) (see, e.g., Ref. 4). Because of the high surface sensitivity of XPS, the observation with this technique implies the presence of $\mathrm{Na}$ on top of the absorber film prior to the preparation of the CdS buffer layer. In addition to its effects on the growth and properties of the absorber layer Na may, therefore, also influence the CdS interface formation. The valence-band discontinuity for $\mathrm{CdS} / \mathrm{CuInSe} \mathrm{C}_{2}$ prepared by UHV evaporation of CdS on single-crystal $\mathrm{CuInSe}_{2}$ has been determined by photoelectron spectroscopy to be $0.8 \mathrm{eV}$. This corresponds to a conduction-band offset of $0.65 \mathrm{eV}$, a value that is obviously not operative in the real solar cell. ${ }^{6}$ For the achieved performance a conduction-band offset close to zero is necessary.

To study the influence of $\mathrm{Na}$ on the $\mathrm{CdS} / \mathrm{CuInSe}{ }_{2}$ interface we investigated in a first step the interaction of sodium with $\mathrm{CuInSe}_{2}$ surfaces. Adsorbate free surfaces which are

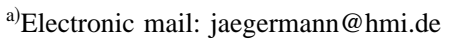

representative of the bulk crystal structure are best suited for this kind of investigation. This is most easily done by cleaving, since sputtering and annealing may lead to deviations of the surface stoichiometry form bulk composition values. ${ }^{7}$ With photoelectron spectroscopy the chemical changes of the surface can be monitored in the course of increasingly deposited amounts of $\mathrm{Na}$.

\section{EXPERIMENT}

The experiments were performed in a commercial UHV chamber (base pressure $3 \times 10^{-11}$ mbar) equipped with an angle resolving hemispherical photoelectron spectrometer (VG ADES 500). The chamber was connected to the TGM 7 beam line of the electron storage ring BESSY in Berlin. Photon energies between 20 and $120 \mathrm{eV}$ were available. The combined resolution of the monochromator and the analyzer, as determined from the Gaussian broadening of the Fermi edge emission of the sputter cleaned metallic sample holder, ranges from 150 to $450 \mathrm{meV}$ for excitation energies $h \nu=20$ $80 \mathrm{eV}$, respectively.

The CuInSe $e_{2}$ crystals were grown by chemical-vapor transport (CVT). As-grown crystals were oriented in (011) direction by x-ray diffraction and cut into pieces. The crystals were fixed to the rapid transfer $\mathrm{Cu}$-sample holders. Notches were put on the crystals for cleavage in the UHV preparation chamber (base pressure $1 \times 10^{-10}$ mbar) with blade/anvil cleaving pincers.

$\mathrm{Na}$ was deposited from a SAES alkali dispenser cell in the preparation chamber. Deposition rates were tuned by the dispenser current. Deposition and characterization was performed at room temperature. All spectra were taken in normal emission. Binding energies are given with respect to the Fermi level.

\section{RESULTS}

Since no calibration of deposition rate for $\mathrm{Na}$ was available, we determined the actual $\mathrm{Na}$ coverages from the evolution of relative intensities of adsorbate to substrate levels. The thickness curve matches closely the applied deposition times and dispenser currents. The maximum Na coverage 


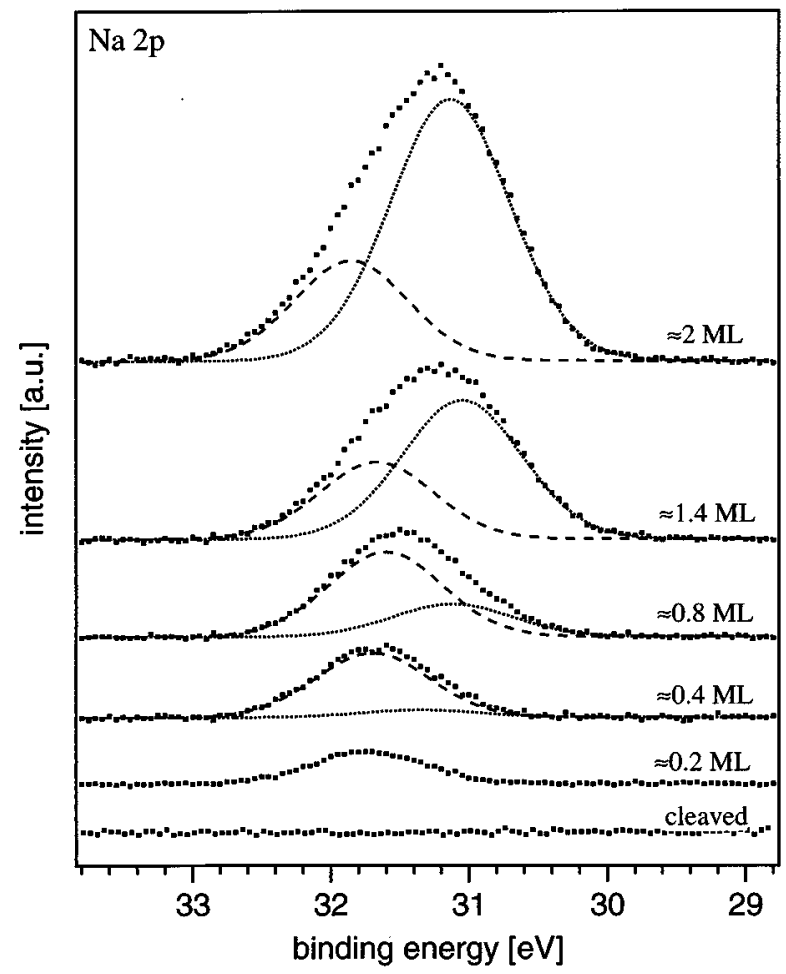

FIG. 1 . Na $2 p$ core level spectra of the $\mathrm{Na} / \mathrm{CuInSe}_{2}$ interface for increasing amounts of deposited Na. An excitation energy of $h \nu=80 \mathrm{eV}$ has been applied.

was estimated from the relative intensities after the last deposition step using tabulated photoionization cross sections ${ }^{8}$ and analyzer transmission as a function of kinetic energy. From this procedure we estimated the maximum amount of deposited $\mathrm{Na}$ to be about 2 monolayers (ML).

In Fig. 1 we show a selection of adsorbate $\mathrm{Na} 2 p$ core levels in the course of increasing $\mathrm{Na}$ deposition. The spectra were excited with photon energy $h \nu=80 \mathrm{eV}$. For low $\mathrm{Na}$ coverage the $\mathrm{Na} 2 p$ line shows a single emission feature at binding energy (BE) of $31.8 \mathrm{eV}$ (the spin-orbit splitting of the Na $2 p$ level cannot be resolved). With further deposition the Na $2 p$ level becomes asymmetrically broadened. The spectra can be deconvoluted into two components as indicated in Fig. 1 by the dotted and dashed curves, respectively. The high-BE component becomes saturated in intensity at a coverage of 0.4-0.5 ML, while the low-BE component at $\mathrm{BE} \approx 31.1 \mathrm{eV}$ increases with increasing $\mathrm{Na}$ deposition. Both components show only small variations in $\mathrm{BE}$ and linewidth with coverage.

Figure 2 shows the evolution of the In $4 d$ substrate emission in the course of deposition of Na. The spectra are taken with an excitation energy of $h \nu=80 \mathrm{eV}$. After deposition of $\approx 0.2 \mathrm{ML}$ the In $4 d$ emissions are shifted to higher $\mathrm{BE}$ (Fermi level moves closer to conduction band) by $\sim 300$ $\mathrm{meV}$ and are slightly broadened. Since the broadening is again reduced with further $\mathrm{Na}$ deposition we attribute it to Fermi-level inhomogeneities due to incomplete surface coverage (see, e.g., Refs. 9 and 10), rather than to a chemical reaction. For deposition of $\approx 0.4 \mathrm{ML}$ a new chemical species is clearly observed at $\mathrm{BE}=16.7 \mathrm{eV}$, characteristic for metal-

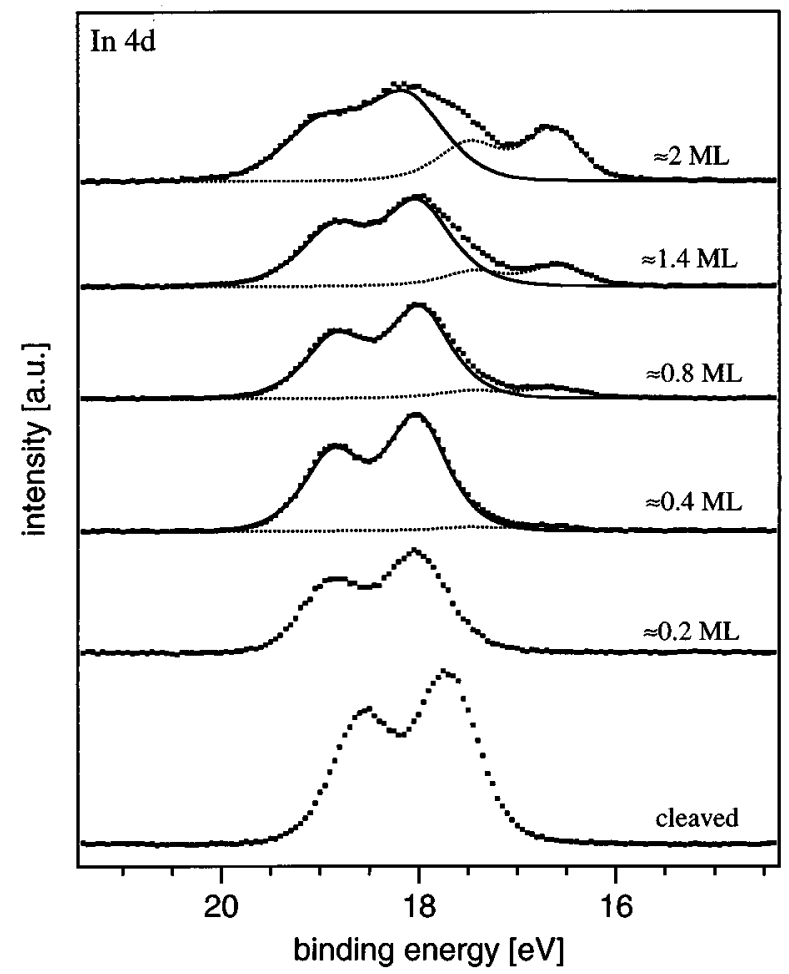

FIG. 2. In $4 d$ core level spectra of the $\mathrm{Na} / \mathrm{CuInSe}{ }_{2}$ interface for increasing amounts of deposited $\mathrm{Na}$. An excitation energy of $h \nu=80 \mathrm{eV}$ has been applied. With increasing $\mathrm{Na}$ deposition, a metallic In component grows in (dotted line). The high-BE component (solid line) broadens for higher $\mathrm{Na}$ coverages and is assumed to contain more than one chemical species.

lic indium. The intensity of the metallic In $4 d$ component increases almost parallel to the intensity of the low-BE $\mathrm{Na} 2 p$ component. The results of a deconvolution of the In $4 d$ levels into two components is indicated in Fig. 2 by the solid and dotted lines. Significant broadening of the high-BE component (solid line) is observed for the highest coverages. In addition a $B E$ shift of $\Delta \mathrm{BE} \approx+120 \mathrm{meV}$ with respect to the spectra obtained after deposition of $\approx 0.2$ and $\approx 0.4 \mathrm{ML}$ sodium is observed. After the final deposition step, the intensity ratio of the metallic to the nonmetallic In $4 d$ emissions is given by $\sim 0.5$.

Figure 3 shows the evolution of the Se $3 d$ core level with increasing $\mathrm{Na}$ deposition. As excitation energy again $h \nu=80 \mathrm{eV}$ has been used. The spectra taken from the freshly cleaved surface clearly exhibits a shoulder on the low-BE side, as also indicated by deconvolution results. We attribute this shoulder to emissions from surface atoms. The surface core level shift (SCLS) is given by $\Delta \mathrm{BE}_{\text {surf }}=-0.4( \pm 0.05)$ $\mathrm{eV}$. The intensity ratio of surface to bulk component amounts to 0.46 . The amplitude and the negative sign of $\Delta \mathrm{BE}_{\text {surf }}$ is comparable to the SCLS commonly observed for the anion levels of the binary 3-5 compounds. ${ }^{11}$ From analogy to the binary semiconductors we would expect the In $4 d$ level to show a SCLS of opposite sign and comparable magnitude. Although there is some asymmetry on the high-BE side of the In $4 d$ level taken from the cleaved surface (see bottom spectrum in Fig. 2), the intensity of this "surface component" is much smaller than that of the respective 


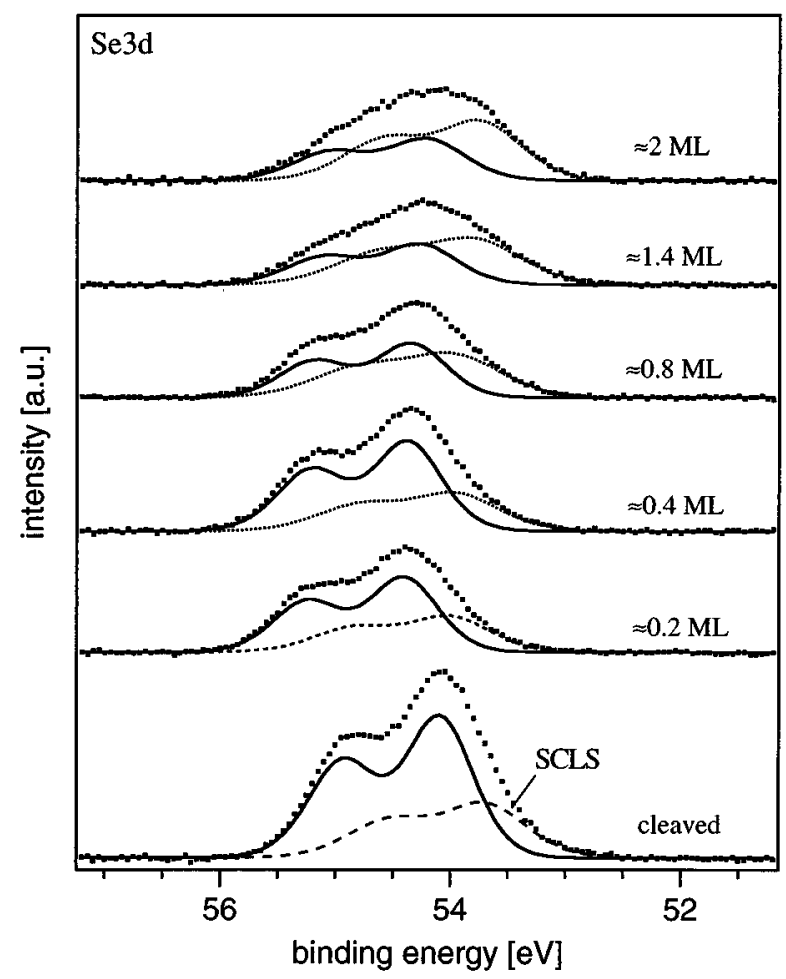

FIG. 3. Se $3 d$ core level spectra of the $\mathrm{Na} / \mathrm{CuInSe}_{2}$ interface for increasing amounts of deposited Na. An excitation energy of $h \nu=80 \mathrm{eV}$ has been applied. The spectrum of the cleaved surface exhibits a surface core level shift of $-0.4( \pm 0.05) \mathrm{eV}$ (dashed line). With increasing Na deposition a chemically shifted component is observed (dotted line) which is assumed to contain more than one chemical species.

Se $3 d$ component. This may be due to the fact that the $\mathrm{In}-\mathrm{Se}$ bond is weak in $\mathrm{CuInSe}_{2}$ as described by Jaffe and Zunger. ${ }^{12}$

The Se $3 d$ emissions originating from $\mathrm{CuInSe}_{2}$ bulk atoms show a BE shift of $\Delta \mathrm{BE} \approx+0.3 \mathrm{eV}$ for initial Na deposition. For the first two deposition steps, the intensity ratio and $\mathrm{BE}$ difference between the two Se $3 d$ components remains almost constant. With further deposition of $\mathrm{Na}$ the low- BE component increases in intensity. The BE difference between the two components increases from 0.4 to $0.46 \mathrm{eV}$ after the last deposition step. The linewidth of the low-BE component remains constant for all deposition steps. After the final deposition step the low-BE component is shifted by $\Delta \mathrm{BE} \approx-100 \mathrm{meV}$ with respect to the spectra obtained after deposition of $\approx 0.2 \mathrm{ML}$. The intensity ratio of the low- to the high-BE component after the final deposition step is given by $\sim 1.5$.

In Fig. 4 we show the valence-band spectra of $\mathrm{CuInSe}_{2}$ excited with $80 \mathrm{eV}$ photons in the course of $\mathrm{Na}$ deposition. From the extrapolation of the onset of photoelectron emission, the energy difference between the valence-band maximum and the Fermi level is $E_{F}-E_{V} \approx 0.4 \mathrm{eV}$ for the cleaved surface. Again the shift to higher BE for initial $\mathrm{Na}$ deposition is observed. For increasing deposition the typical valenceband features of CuInSe $\mathrm{S}_{2}$ are completely lost, however, significant changes of the valence-band structure are already observed after deposition of $\approx 0.2 \mathrm{ML}$. This is evident from the difference spectra that are shown at the bottom of Fig. 4. To obtain the difference spectra we multiplied the spectrum

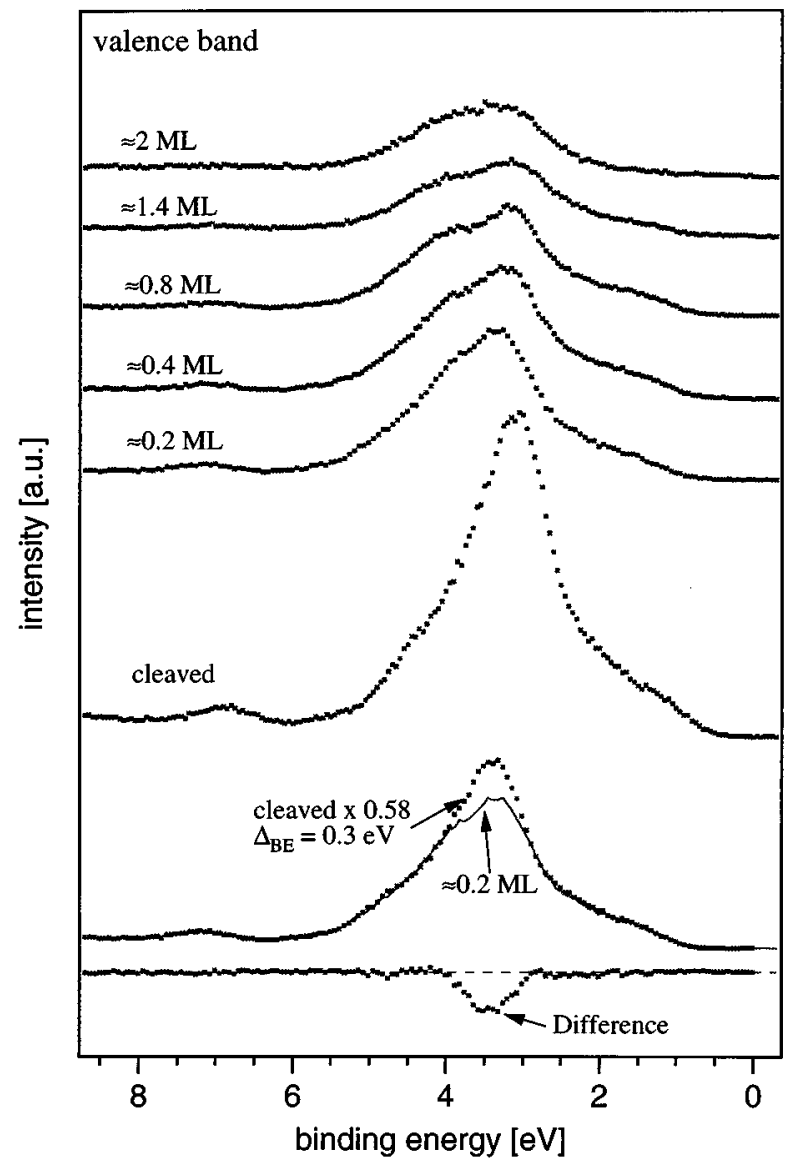

FIG. 4. Valence-band spectra of the $\mathrm{Na} / \mathrm{CuInSe}_{2}$ interface for increasing amounts of deposited $\mathrm{Na}$ and difference spectra of valence bands taken from cleaved surface and after deposition of $\approx 0.2 \mathrm{ML} \mathrm{Na}$. For difference formation the spectrum from the cleaved surface has been shifted by $\Delta \mathrm{BE}=+0.3$ $\mathrm{eV}$ and multiplied by 0.58 . All spectra were recorded with an excitation energy of $h \nu=80 \mathrm{eV}$.

of the cleaved surface by a factor of 0.58 and shifted its $\mathrm{BE}$ by $\Delta \mathrm{BE}=+0.30 \mathrm{eV}$. These values are adopted without any further modification from $\mathrm{BE}$ and intensity changes of the corresponding In $4 d$ spectra. Finally, the modified spectrum is subtracted from the one obtained after deposition of $\approx 0.2$ ML Na. The difference is zero for most BE, justifying the applied procedure; however, at $\mathrm{BE}$ around $\mathrm{BE}=2.8 \mathrm{eV}$ there is a considerable intensity loss induced by $\mathrm{Na}$ deposition.

The evolution of the sample work function as function of $\mathrm{Na}$ deposition is shown in Fig. 5. With photoelectron spectroscopy the work function is determined from the cutoff of secondary electron emission. For the cleaved surface we obtained a work function of $\phi=5.25 \mathrm{eV}$. Together with $E_{F}$ - $E_{V} \approx 0.4 \mathrm{eV}$ (see above), this corresponds to an ionization energy of $I_{p} \approx 5.65 \mathrm{eV}$ and with $E_{g}=1.04 \mathrm{eV},{ }^{1}$ to an electron affinity of $\chi=4.6( \pm 0.15) \mathrm{eV}$. With increasing Na deposition the work function decreases monotonically and seems to saturate at a value of $\varphi=3.6 \mathrm{eV}$.

\section{DISCUSSION}

Obviously UHV-cleaved (011) surfaces of $\mathrm{CuInSe}_{2}$ and sodium form a chemically reactive interface. This is most evident from the appearance of the metallic In $4 d$ compo- 


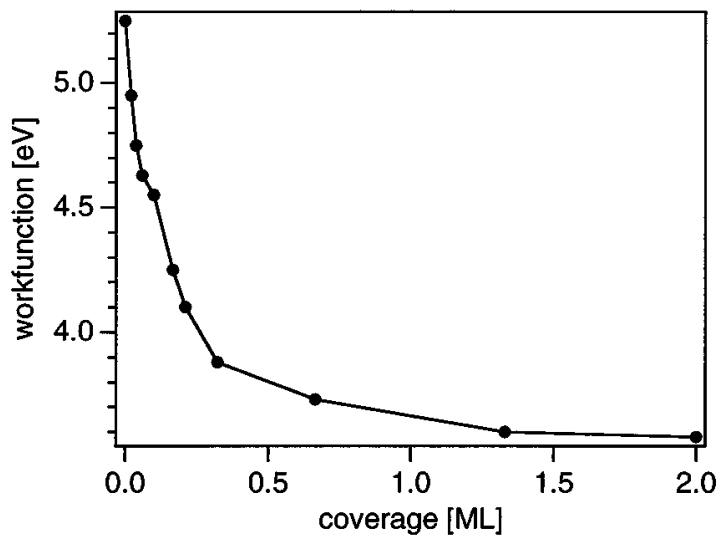

FIG. 5. Evolution of work function for $\mathrm{CuInSe}_{2}$ in the course of $\mathrm{Na}$ deposition. The work function has been derived from the extrapolation of the secondary electron cutoff of valence-band spectra taken with $h \nu=21 \mathrm{eV}$.

nent, which indicates the decomposition of the substrate, at least for higher $\mathrm{Na}$ coverage. For smaller coverages no change of substrate core level emissions is observed. Therefore, a division between a high- and low-coverage regime can be drawn which is also corroborated from the evolution of the $\mathrm{Na} 2 p$ core level.

For low coverages a $\mathrm{Na} 2 p$ component with a higher $\mathrm{BE}$ than for the reacted state is observed. Identical behavior of the $\mathrm{Na} 2 p$ level has been observed by Prietsch et al. for $\mathrm{Na}$ deposited on cleaved GaAs substrates. ${ }^{13}$ The higher BE of the $\mathrm{Na} 2 p$ level at low coverages has been attributed to $\mathrm{Na}^{+}$ ions adsorbed on the surface. The transfer of electrons to the substrate is reflected in the band bending induced by $\mathrm{Na}$ deposition. The intensity of $\mathrm{Na}^{+}$should therefore saturate in parallel with the band bending as indeed observed for $\mathrm{Na}$ on GaAs. ${ }^{13}$ For nonreactive interfaces this saturation generally occurs already at very low coverages, i.e., considerably less than 0.1 ML. ${ }^{11}$ However, as evident from Fig. 1, the intensity of the high-BE component saturates after 0.4-0.5 ML coverage for the $\mathrm{Na} / \mathrm{CuInSe}{ }_{2}$ interface, while the band bending is already fully developed after 0.2 ML (or even less).

Although there is no evidence from core levels for an interface reaction at low $\mathrm{Na}$ coverage, the valence-band difference spectra in Fig. 4 show a significant loss of substrate emissions at $\mathrm{BE} \approx 2.8 \mathrm{eV}$. This $\mathrm{BE}$ regime corresponds to the most intense valence-band emissions at an excitation energy of $h \nu=80 \mathrm{eV}$. Because of the energy dependence of photoionization cross sections ${ }^{8}$ the valence bands taken at higher photon energies only reflect the contribution of $\mathrm{Cu}$ to the density of states. ${ }^{14,15}$ The intensity loss for low coverages is thus most likely explained by a stoichiometric reduction of $\mathrm{Cu}$ within the sampling depth $(\sim 10 \AA)$. As pointed out by Jaffe and Zunger, and optical band-gap transition in $\mathrm{CuInSe}_{2}$ stabilizes the $\mathrm{Cu}-\mathrm{Se}$ bonds, because an electron is removed from the antibonding $\mathrm{Cu} 3 d-\mathrm{Se} 4 p$ orbital combinations. ${ }^{12}$ The donation of electrons into the $\mathrm{Cu} 4 s$ conduction states by electropositive adsorbates may in turn lead to breaking of $\mathrm{Cu}-\mathrm{Se}$ bonds. Diffusion of $\mathrm{Cu}^{+}$ions into the substrate is then favored by the electric field at the surface which is induced by band bending.
The release of $\mathrm{Cu}$ from crystallographic positions and subsequent diffusion of $\mathrm{Cu}^{+}$into the bulk also explains the large amount of $\mathrm{Na}^{+}$species observed. We expect $\mathrm{Cu}$ vacancies in $\mathrm{CuInSe}_{2}$ to act as electron acceptor states, since the missing $\mathrm{Cu} 3 d$ electrons, which constitute the $\mathrm{Cu}-\mathrm{Se}$ bonds, will create holes in the conduction band. These will compensate the electron donation from adsorbed $\mathrm{Na}$. Hence, a larger amount of $\mathrm{Na}^{+}$is required to maintain the induced band bending. Thin films of $\mathrm{CuInSe}_{2}$ grown on sodium-containing substrates show an increased $p$-type conductivity. ${ }^{16}$ This corroborates our explanation of acceptor formation induced by $\mathrm{Na}$ deposition. Finally the question arises whether $\mathrm{Cu}$ vacancies are stable in the presence of $\mathrm{Na}$. Incorporation of $\mathrm{Na}$ on $\mathrm{Cu}$ vacancies would create $\mathrm{Na}-\mathrm{Se}$ bonds and is thus expected to be energetically favorable. This energy gain might also be crucial for the removal of $\mathrm{Cu}$ from its equilibrium lattice position. However, the substitution of $\mathrm{Cu}$ by $\mathrm{Na}$ remains to be experimentally verified.

The lower-BE species of $\mathrm{Na}$ observed at higher coverages might be assigned to metallic $\mathrm{Na}$; however, metallic $\mathrm{Na}$ exhibits a much smaller work function $\left(\Phi_{\mathrm{Na}}=2.75 \mathrm{eV}\right)^{17}$ than determined for our reacted overlayer $\left(\Phi_{\mathrm{Na} / \mathrm{CuInSe}_{2}}=3.6 \mathrm{eV}\right.$; see Fig. 5). Moreover, for metallic $\mathrm{Na}$ a plasmon loss structure should be observed on the high-BE side of the $\mathrm{Na} 2 p$ line which is not the case in our experiment. Therefore, we attribute the low-BE component of the $\mathrm{Na} 2 p$ line to $\mathrm{Na}_{2} \mathrm{Se}$ formed by chemical decomposition of $\mathrm{CuInSe}_{2}$. This assignment is supported by the appearance of a metallic In component. It is also consistent with a photoemission investigation of the chemically reactive interface of $\mathrm{Na}$ with $\mathrm{InSe}$ where comparable $\mathrm{Na} 2 p$ and valence-band spectra have been observed. ${ }^{18}$ The formation of $\mathrm{Na}_{2} \mathrm{Se}$ is further reflected in the low-BE component of the Se $3 d$ level which grows with increasing $\mathrm{Na}$ deposition as also observed for the $\mathrm{Na} / \mathrm{InSe}$ interface. $^{18}$

The high-BE component of the $\mathrm{Se} 3 d$ - and the In $4 d$ levels both directly evolve from the $\mathrm{CuInSe}_{2}$ species; therefore, they might be attributed to undisrupted $\mathrm{CuInSe}_{2}$. However, the two components show different behavior of $\mathrm{BE}$ for higher $\mathrm{Na}$ coverages (see above). In addition the relative intensities of the reacted Se $3 d$ - to the high-BE Se $3 d$ component is three times that of the metallic In $4 d$ - to the high-BE In $4 d$ component. Moreover, there is an increase in linewidth of the high-BE In $4 d$ component for higher $\mathrm{Na}$ coverages. These observations clearly indicate the presence of further chemical species which contribute to the high-BE In $4 d$ - and to the low-BE Se $3 d$ component, respectively. Therefore, it is only the low-BE species of the Se $3 d$ level that still represents undisrupted $\mathrm{CuInSe}_{2}$. Possible candidates of the spectroscopically unidentified products of the chemical decomposition are $\mathrm{InSe}, \mathrm{Cu}_{2} \mathrm{Se}$, or any combinations of these. There is no way for the determination of the relative amount of these additional species from the presented data, especially because of their unknown spatial distribution. It is not expected that curve fitting the In $4 d$ - and Se $3 d$ spectra with more than two components will give reliable results, because fitting with two components already gives quite good agreement with the data. 
As outlined above a depletion of $\mathrm{Cu}$ occurs for initial $\mathrm{Na}$ deposition. It is thus also possible that for intermediate amounts of $\mathrm{Na}$ a vacancy compound like $\mathrm{CuIn}_{3} \mathrm{Se}_{5}$ is formed. This compound is of technological importance in $\mathrm{CuInSe}_{2}$ thin-film solar cell structures because of their role in establishing the band discontinuity, especially the small conduction-band offset, at the CdS/CuInSe ${ }_{2}$ interface. ${ }^{6}$ Further chemical decomposition may proceed from this intermediate compound.

\section{SUMMARY AND CONCLUSIONS}

The chemical interaction of $\mathrm{Na}$ with UHV-cleaved $\mathrm{CuInSe}_{2}$ (011) surfaces has been studied with synchrotron excited photoelectron spectroscopy. The cleaved surfaces exhibit an electron affinity of $4.6( \pm 0.1) \mathrm{eV}$. A surface core level shift of $\Delta \mathrm{BE}_{\text {surf }}=-0.4( \pm 0.05) \mathrm{eV}$ is observed for the $\mathrm{Se} 3 d$ level. Initially $\mathrm{Na}$ adsorbs as $\mathrm{Na}^{+}$ions on the surface which is a consequence of its electropositive character. The donation of electrons to the substrate induces a band bending and leads to the breaking of $\mathrm{Cu}-$ Se bonds. Released $\mathrm{Cu}^{+}$ diffuses into the substrate driven by the electric field. The amount of $\mathrm{Na}^{+}$species observed on the surface is unusually large and exceeds the concentration necessary for band bending several times. This is explained by the formation of electron acceptor states induced by $\mathrm{Na}$ deposition, probably accompanied by replacement of $\mathrm{Cu}$ by $\mathrm{Na}$. With increasing $\mathrm{Na}$ deposition new chemical species are formed by decomposition of CuInSe${ }_{2}$. Only metallic indium and $\mathrm{Na}_{2} \mathrm{Se}$ can be identified unambiguously. However, also InSe and $\mathrm{Cu}_{2} \mathrm{Se}$ may form as is evident from a detailed analysis of core levels as well as from stoichiometric considerations. In the decomposition reaction vacancy compounds like $\mathrm{CuIn}_{3} \mathrm{Se}_{5}$ may be formed as intermediate reaction steps.

${ }^{1}$ J. L. Shay and J. H. Wernick, Ternary Chalcopyrite Semiconductors (Pergamon, Oxford, 1975)

${ }^{2}$ K. Bücher and S. Kunzelmann, in Proceedings of the 13th European Photovoltaic Solar Energy Conference, Nice, 1995, p. 2352.

${ }^{3}$ J. Hedström, H. Ohlsen, M. Bodegård, A. Kylner, L. Stolt, D. Hariskos, M. Ruckh, and H. W. Schock, in Proceedings of the 23rd IEEE Photovoltaic Specialists Conference, Louisville, KY, 1993, p. 364.

${ }^{4}$ C. Heske, R. Fink, D. Jacob, and E. Umbach, in Proceedings of the 13th European Photovoltaic Solar Energy Conference, Nice, 1995, p. 2003.

${ }^{5}$ T. Löher, W. Jaegermann, and C. Pettenkofer, J. Appl. Phys. 77, 731 (1995)

${ }^{6}$ D. Schmid, M. Ruckh, F. Grunwald, and H. W. Schock, J. Appl. Phys. 73, 2902 (1993)

${ }^{7}$ T. Löher, C. Pettenkofer, and W. Jaegermann, in Proceedings of the First World Conference on Photovoltaic Energy Conversion, Hawaii, 1994, p. 295.

${ }^{8}$ J. J. Yeh and I. Lindau, At. Data Nucl. Data Tables 32, 2 (1985).

${ }^{9}$ R. Schlaf, A. Klein, C. Pettenkofer, and W. Jaegermann, Phys. Rev. B 48, 14242 (1993)

${ }^{10}$ A. Klein, C. Pettenkofer, W. Jaegermann, M. Lux-Steiner, and E. Bucher, Surf. Sci. 321, 19 (1994).

${ }^{11}$ W. Mönch, Semiconductor Surfaces and Interfaces (Springer, Heidelberg, 1993).

${ }^{12}$ J. E. Jaffe and A. Zunger, Phys. Rev. B 28, 5822 (1983).

${ }^{13}$ M. Prietsch, M. Domke, C. Laubschat, T. Mandel, C. Xue, and G. Kaindl, Z. Phys. B 74, 21 (1989).

${ }^{14}$ W. Braun, A. Goldmann, and M. Cardona, Phys. Rev. B 10, 5069 (1974).

${ }^{15}$ T. Löher, A. Klein, C. Pettenkofer, and W. Jaegermann (unpublished).

${ }^{16}$ H. W. Schock, Adv. Solid State Phys. 34, 147 (1994).

${ }^{17}$ R. J. Whitefield and J. J. Brady, Phys. Rev. Lett. 26, 380 (1971).

${ }^{18}$ A. Schellenberger, R. Schlaf, C. Pettenkofer, and W. Jaegermann, Solid State Ion. 66, 307 (1993).

This article may be downloaded for personal use only. Any other use requires prior permission of the author and AIP Publishing. This article appeared in Journal of Applied Physics 80, 5039 (1996) and may be found at https://doi.org/10.1063/1.363549.

Available under only the rights of use according to UrhG. 